University of Nebraska - Lincoln

DigitalCommons@University of Nebraska - Lincoln

Nebraska Cooperative Fish \& Wildlife Research Nebraska Cooperative Fish \& Wildlife Research Unit -- Staff Publications

2006

\title{
Multiple hypotheses testing of fish incidence patterns in an urbanized ecosystem
}

Christopher J. Chizinski

Texas Tech University, cchizinski2@unl.edu

C.L. Higgins

Tarleton State University

C.E. Shavlik

Minnesota Department of Natural Resources, Division of Fisheries

Kevin L. Pope

University of Nebraska-Lincoln, kpope2@unl.edu

Follow this and additional works at: https://digitalcommons.unl.edu/ncfwrustaff

Part of the Other Environmental Sciences Commons

Chizinski, Christopher J.; Higgins, C.L.; Shavlik, C.E.; and Pope, Kevin L., "Multiple hypotheses testing of fish incidence patterns in an urbanized ecosystem" (2006). Nebraska Cooperative Fish \& Wildlife Research Unit -- Staff Publications. 9.

https://digitalcommons.unl.edu/ncfwrustaff/9

This Article is brought to you for free and open access by the Nebraska Cooperative Fish \& Wildlife Research Unit at DigitalCommons@University of Nebraska - Lincoln. It has been accepted for inclusion in Nebraska Cooperative Fish \& Wildlife Research Unit -- Staff Publications by an authorized administrator of DigitalCommons@University of Nebraska - Lincoln. 


\title{
Multiple hypotheses testing of fish incidence patterns in an urbanized ecosystem
}

\author{
C.J. Chizinski ${ }^{1, *}$, C.L. Higgins ${ }^{2,3}$, C.E. Shavlik ${ }^{1,4}$ and K.L. Pope ${ }^{1,5}$ \\ ${ }^{1}$ Wildlife and Fisheries Management Institute, Texas Tech University Lubbock, Mail Stop 2125, Lubbock, TX, \\ 79409-2125, USA; ${ }^{2}$ Department of Biological Sciences, Texas Tech University Lubbock, Lubbock, TX, 79409- \\ 3131, USA; ${ }^{3}$ Department of Biological Sciences, Tarleton State University, Stephenville, TX, 76402, USA; \\ ${ }^{4}$ Minnesota Department of Natural Resources, Division of Fisheries, 07316 State $371 \mathrm{NW}$, Walker, MN, 56484, \\ USA; ${ }^{5}$ USGS - Nebraska Cooperative Fish and Wildlife Research Unit, University of Nebraska-Lincoln, 103 \\ Miller Hall, Lincoln, NE,68583-0711, USA;*Author for correspondence (e-mail: chris.chizinski@ttu.edu; \\ phone: +1-806-742-1981; fax: +1-806-742-2280)
}

Received 21 April 2005; accepted in revised form 14 November 2005

Key words: Fish assemblages, Invasion, Model selection, Urban

\begin{abstract}
Ecological and evolutionary theories have focused traditionally on natural processes with little attempt to incorporate anthropogenic influences despite the fact that humans are such an integral part of virtually all ecosystems. A series of alternate models that incorporated anthropogenic factors and traditional ecological mechanisms of invasion to account for fish incidence patterns in urban lakes was tested. The models were based on fish biology, human intervention, and habitat characteristics. However, the only models to account for empirical patterns were those that included fish invasiveness, which incorporated speciesspecific information about overall tolerance and fecundity. This suggests that species-specific characteristics are more important in general distributional patterns than human-mediated dispersal. Better information of illegal stocking activities is needed to improve human-mediated models, and more insight into basic life history of ubiquitous species is needed to truly understand underlying mechanisms of biotic homogenization.
\end{abstract}

\section{Introduction}

Ecological and evolutionary theories have traditionally focused on natural processes with little attempt to incorporate anthropogenic influences. For example, the theory of island biogeography (MacArthur and Wilson 1963, 1967) describes how the dynamic relationship between immigration and extinction affects patterns of species richness on islands of different size and different distance from the mainland. Island biogeography has been applied to a variety of 'island' systems, whether they are islands within an archipelago, sets of habitat patches, or isolated mountaintops. However, the biological insight gained from examining immigration and extinction on islands was based solely on organismal biology and did not account for human interventions, which currently dominate these processes for many organisms. Humans are such an integral part of virtually all ecosystems that they must be incorporated into current views of ecology and evolutionary biology (McDonnell and Pickett 1993; Vitousek et al. 1997).

Humans use and modify the environment through agriculture, forestry, and urbanization. These activities, particularly urbanization, are 
altering ecosystem function (Vitousek et al. 1997; Grimm et al. 2000), reducing the biological uniqueness of local ecosystems (Olden et al. 2004), and altering biodiversity at a variety of spatial scales (McKinney 2002; Turner et al. 2004). Although each of these activities affects biodiversity as a whole, it is increasingly important to examine the specific attributes to gain a holistic understanding of human impacts on biodiversity. For example, the reduction of biological uniqueness (i.e., biotic homogenization) is often considered one of the most important signs of biological impoverishment (Olden et al. 2004). Humans have been a prime component in reducing biological uniqueness of communities through humanmediated dispersal at multiple scales (Rahel 2000, 2002). The result is biotic homogenization, a global phenomenon in which species composition among communities becomes more similar through time (McKinney and Lockwood 1999). This pattern has been observed in a variety of taxa, including plants (McKinney and Lockwood 2001; Rooney et al. 2004), butterflies (Blair 2001), snails (Cowie 2001), fishes (Radomski and Goeman 1995; Rahel 2000, 2002; Scott and Helfman 2001; Marchetti et al. 2001), amphibians (Duncan and Lockwood 2001), reptiles (Wilson 1997), birds (Lockwood et al. 2000; Blair 2001), and mammals (Wilson 1997). In fact, contemporary patterns of biotic homogenization are so widespread that the current geological epoch (i.e., Holocene) has been referred to as the 'Homogecene' (Rosenzweig 2001).

Despite our understanding of the patterns of biotic homogenization, the mechanisms driving it remain elusive. Intuitively, the combined negative consequences of both extinctions and introductions lead to rapid loss in regional distinction of species (Tilman 1999; Mack et al. 2000), although extinctions and introductions do not necessarily have to act simultaneously in order to increase similarity among communities (Olden and Poff 2004). The extinctions of specialists result in biota that is comprised primarily of generalists, which increases similarity of biotic structure and function. Today, extinctions are primarily the result of human interactions, particularly habitat fragmentation and land transformation (Olden and Poff 2004; Turner et al. 2004). Furthermore, extinctions from human activities are even more common, which affect regional diversity (Rahel 2000). Introductions alone can give rise to biotic homogenization by introducing exotic species that dominate new environments. Although introductions can occur naturally, they are frequently initiated through human activity, especially in urban environments (Moyle and Light 1996; Kolar and Lodge 2002; Rahel 2002) and aquatic systems (Rahel 2000, 2002). Though patterns of biotic homogenization are due to extinctions and introductions, introductions are responsible for the bulk of the homogenization because there have been many more introductions than extinctions. This is particularly true in aquatic systems because little diversity exists among introduced fishes, which chiefly have comprised cosmopolitan game and food fishes such as largemouth bass Micropterus salmoides, brown trout Salmo trutta, and rainbow trout Oncorhynchus mykiss (Rahel 2000).

Although ecologists understand that humans affect ecosystems worldwide, few studies of urban ecology have attempted to actually incorporate humans as potential structuring mechanisms of biotic homogenization. Those that have attempted to include human components were unable to distinguish the effects of anthropogenic activities between extinctions and introduction processes. Invasion 'melting-pots' tend to occur in urban areas where the effect of human activity is concentrated; thus, urban centers offer important opportunities to gain insight into the underlying mechanisms of biotic homogenization. Because we investigated lakes that were between 10 and 50 years old, we focused purely on mechanisms of invasion without associated interactions with extinction-based mechanisms. The purpose of this study was to assess mechanisms of invasion as an important step in understanding the mechanisms behind biotic homogenization in an urban ecosystem by incorporating anthropogenic forces with tradition ecological mechanisms.

\section{Materials and methods}

Data

Within the municipality of Lubbock, TX, there are numerous urban lakes, most of which were playa lakes modified for management of stormwater (Schramm et al. 1992). In addition to water storage, they also provide recreational fishing opportunity for citizens. Although fishes originally were 
unable to colonize these ephemeral wetlands, the altered hydrology created permanent lakes that support viable populations of fishes within the municipality (Smith 2003); this setting provided a unique opportunity to assess invasions without confounding effects of extinctions. Some of the more common fishes found in these urban waters are bluegill Lepomis macrochirus, common carp Cyprinus carpio, gizzard shad Dorosoma cepedianum, goldfish Carassius auratus, largemouth bass and white crappie Pomoxis annularis (Shavlik 2000).

The composition of fish communities was determined in 17 Lubbock lakes via daytime electrofishing (pulsed DC) during June 1999. Two people in the front of a boat equipped with a Smith-Root 5.0 GPP electrofisher dip-netted all stunned fishes. Captured fishes were identified to species and released alive. Electrofishing effort was 10 min per lake except for two smaller lakes in which the entire shoreline was sampled in 8 9 min. During sampling, water temperature and conductivity ranged from 22.8 to $26.5^{\circ} \mathrm{C}$ and from 130 to $348 \mu \mathrm{S} \mathrm{cm}^{-1}$, respectively. Thus, only minor differences in power transfer, which is directly related to electrofishing efficiency (Kolz and Reynolds 1990; Reynolds 1996), existed among lakes. This, in combination with relatively constant effort, provided a similar sampling scheme among all lakes, which is important when assessing metacommunity structure (Selmi and Boulinier 2004).

\section{Multiple working hypotheses}

Multiple hypotheses were developed from several possible invasion mechanisms to describe the distribution of fishes in urban lakes. The alternate hypotheses were based on fish biology, human intervention, and habitat characteristics. In addition, null models that described what expected patterns would look like in the absence of specific ecological mechanisms were incorporated in the suite of models. Each of these factors were quantified and converted to probability vectors (Appendices A and B) and combined in various combinations to produce probability matrices, each corresponding to a different alternate hypothesis.

\section{Null models and vectors}

Null models are pattern-generating models that are based on randomization of ecological data or random sampling from known distributions (Gotelli and Graves 1996). The null models used were based on random sampling from uniform distributions of lake characteristics and species composition. The lake vector (LAKE), which was created by taking the inverse of the number of lakes $\left(N_{\mathrm{LAKE}}=17\right)$ and assigning that value to each lake, ensured that lake characteristics played no role in producing expected patterns of species composition (i.e., each species had equal probability of occurring in any given lake). The species vector (SPEC) was created in a similar fashion as $\operatorname{LAKE}\left(N_{\mathrm{SPEC}}=12\right)$ and ensured that species occurrence in any given lake was independent of biological or anthropogenic interactions (i.e., each lake had equal probability of containing any given species).

\section{Fish biology vector}

Invasiveness is an important characteristic of species establishing new populations (Moyle and Light 1996; Kolar and Lodge 2002). Therefore, it was hypothesized that urban lakes would be dominated by the most invasive fish species. Because there is no established listing of species invasiveness, an invasiveness vector (INVA) was estimated using published information on species tolerance (Linam et al. 2002) and fecundity (Table 1), which are the two primary characteristics of successful invaders (Moyle and Light 1996; Kolar and Lodge 2002; Marchetti et al. 2004). Tolerance of fishes was established with a survey that asked fish biologists to categorize fish species as tolerant, moderately tolerant, or intolerant (Linam et al. 2002). We subjectively coded tolerant species as 2 and moderately tolerant species as 1 and multiplied these values with each species corresponding median fecundity to create INVA, because a tolerant species that is very fecund is more likely to become established in a new environment than an intermediately tolerant species of equal fecundity.

\section{Human intervention vector}

Humans are a major source of organismal introductions in urban settings (Lever 1996). 
Table 1. Ichthyofauna of urban lakes in Lubbock, TX, along with their corresponding tolerance level and mean fecundity.

\begin{tabular}{llll}
\hline Species & Common name & Tolerance & Fecundity (mean number of eggs) \\
\hline Ameiurus melas & Black bullhead & Tolerant & $7900^{\mathrm{b}}$ \\
Carassius auratus & Goldfish & Tolerant & $14,000^{\mathrm{c}}$ \\
Cyprinus carpio & Common carp & Tolerant & $1,122,000^{\mathrm{d}}$ \\
Dorosoma cepedianum & Gizzard shad & Tolerant & $186,340^{\mathrm{e}}$ \\
Ictalurus punctatus & Channel catfish & Tolerant & $355,00^{\mathrm{b}}$ \\
Lepomis cyanellus & Green sunfish & Tolerant & $6000^{\mathrm{f}}$ \\
Lepomis humilis & Orangespotted sunfish & Moderate & $2375^{\mathrm{g}}$ \\
Lepomis macrochirus & Bluegill & Tolerant & $34,725^{\mathrm{h}}$ \\
Lepomis megalotis & Longear sunfish & Moderate & $12,240^{\mathrm{i}}$ \\
Micropterus salmoides & Largemouth bass & Moderate & $55,001^{\mathrm{j}}$ \\
Pomoxis annularis & White crappie & Moderate & $163,324^{\mathrm{k}}$ \\
Pomoxis nigromaculatus & Black crappie & Moderate & $37,796^{\mathrm{h}}$
\end{tabular}

References include: ${ }^{\mathrm{a}}$ Linam et al. (2002); ${ }^{\mathrm{b}}$ Carlander (1953); ${ }^{\mathrm{c}}$ Moyle (1976); ${ }^{\mathrm{d}}$ Swee and McCrimmon (1966); ${ }^{\mathrm{e}}$ Bodola (1966); ${ }^{\mathrm{f}} \mathrm{Beckman}$ (1952); ${ }^{\mathrm{g}}$ Toetz (1965); ${ }^{\mathrm{h}} \mathrm{Scott}$ and Crossman (1973); ${ }^{\mathrm{i}}$ Lopinot (1961); ${ }^{\mathrm{j}}$ Kelly (1962); ${ }^{\mathrm{k}}$ Morgan (1954).

Texas Parks and Wildlife Department (TPWD), the agency responsible for management of fisheries in Lubbock, introduced three (bluegill, channel catfish Ictalurus punctatus, and largemouth bass) of the 12 species collected during this study in these urban lakes. The other nine species were either introduced illegally or invaded naturally. Illegal introductions are a common phenomenon that result from the aquarium trade (Courtenay and Stauffer 1990), bait-bucket introductions (Ludwig and Leitch 1996), and intentional stockings (McMahon and Bennett 1996). In fact, human introduction of fishes in these urban lakes were believed to be the primary mechanism for establishment of fish populations because a transport mechanism is needed to move fish across land into these relatively isolated systems that did not historically contain fish populations. There is no established record for the extent of illegal introductions in urban lakes, but it is reasonable to suspect that human introductions are positively related to fishing preference. Fishing preference was estimated from responses to telephone interviews (unpublished data) in which a random sample of Lubbock citizens were asked to identify their preferred fish species. The human vector (HUMN) was defined as the percentage of respondents that identified a fish as their preferred species to catch within the municipality. Species not explicitly identified as preferred (i.e., black bullhead Ameiurus melas, gizzard shad, goldfish, green sunfish Lepomis cyanellus, longear sunfish L. megalotis, and orangespotted sunfish L. humilis) were assigned equal shares of the probability for the 'other' category.

\section{Habitat characteristic vectors}

Habitat characteristics were based on the theory of island biogeography (MacArthur and Wilson 1963, 1967) and included average distance to all lakes and lake area. Distance among lakes was incorporated because natural dispersion of fishes from one lake to another lake is most likely to occur when the lakes are in close proximity (Oliver et al. 2004). It may have been possible for some species of fish to move among urban lakes during spates when some lakes become connected by flowing runoff. Thus, it was hypothesized that similarity of fish assemblages would be greater among geographically close water bodies compared to more distant waters. Straight-line distances (nearest $0.24 \mathrm{~km}$ ) were measured between all lake-pair combinations from a Lubbock City road map and the mean distance $(\mathrm{km})$ from each lake to all other lakes was calculated. The distance vector (DIST) was the inverse of mean distance relative to the total mean distance for all lakes, which was used to ensure that closer lakes would have a greater probability of species occurrence than more distant lakes. Lake area was assessed because species diversity is directly related to size of an ecological system (Connor and McCoy 1979). It was speculated that larger lakes would attract a greater number of anglers, which would magnify the opportunity for human introductions. 
The area vector (AREA) was defined as the surface area relative to the total surface area for all 17 lakes.

\section{Alternate hypotheses}

All probability vectors were relative proportions (i.e., each summed to 1). Each of the vectors was used to create probability matrices that corresponded to a specific hypothesis (Table 2). Hypothesis 1 (LS) corresponded to the null hypothesis that all species have an equal probability of occurrence in all lakes. Hypothesis 2 (LI) predicted a greater occurrence by the more invasive species. Hypothesis $3(\mathrm{LH})$ predicted greater occurrence of the species most sought after by urban anglers. Hypothesis 4 (AS) was one portion of the island biogeography hypothesis and predicted that larger lakes would be colonized more frequently by any given species of fish than smaller lakes. Hypothesis 5 (DS) was the other portion of the island biogeography hypothesis and predicted a greater occurrence of species in lakes of close geographic proximity. In addition to these simple hypotheses, several interactions were also examined. Hypothesis 6 (AI) combined the area and invasive vectors, which predicted greater occurrence of the more invasive species while incorporating greater occurrence of fishes in larger lakes. Likewise, hypothesis 7 (DI) combined the distance and invasive vectors, hypothesis $8(\mathrm{AH})$ combined the area and human-preference vectors, and hypothesis $9(\mathrm{DH})$ combined the distance and human-preference vectors.

\section{Model fitting}

In order to determine which of the proposed hypotheses best accounted for observed patterns of fish composition in urban lakes that was based on field collected (electrofishing) data, fish species were placed probabilistically into the hypothesized matrices to create expected incidence patterns. Each incidence pattern was constrained only by the total number of occurrences within each lake. Jaccard's distance measure (Jaccard 1908), based on binary (presence/absence) data was calculated for each of the expected distributions and compared to the observed distance matrix using Mantel's test (Mantel 1967). This process was repeated for 1000 iterations to characterize expected incidence patterns and obtain

Table 2. Summary of the nine alternate hypotheses developed to account for the spatial distribution of fishes in urban lakes.

\begin{tabular}{|c|c|c|c|}
\hline Alternate hypotheses & Probability vectors used & Number of parameters & Description \\
\hline $\mathrm{LS}$ & $\mathrm{LAKE} \times \mathrm{SPEC}$ & 0 & $\begin{array}{l}\text { Each species has an equal probability } \\
\text { of occurrence in all lakes }\end{array}$ \\
\hline LI & LAKE $\times$ INVA & 1 & $\begin{array}{l}\text { Invasive species have greater probabilities } \\
\text { of occurrence in all lakes }\end{array}$ \\
\hline LH & $\mathrm{LAKE} \times \mathrm{HUMN}$ & 1 & $\begin{array}{l}\text { Fishes most preferred by anglers have greater } \\
\text { probabilities of occurrence in all lakes }\end{array}$ \\
\hline AS & $\mathrm{AREA} \times \mathrm{SPEC}$ & 1 & $\begin{array}{l}\text { Larger lakes are more likely to be colonized by all } \\
\text { species than smaller lakes }\end{array}$ \\
\hline DS & DIST $\times$ SPEC & 1 & $\begin{array}{l}\text { Lakes in close proximity are more likely to be } \\
\text { colonized by all species than distant lakes }\end{array}$ \\
\hline AI & AREA $\times$ INVA & 2 & $\begin{array}{l}\text { Larger lakes are more likely to be colonized by } \\
\text { invasive species than smaller lakes }\end{array}$ \\
\hline DI & DIST $\times$ INVA & 2 & $\begin{array}{l}\text { Lakes in close proximity are more likely to be } \\
\text { colonized by invasive species than distant lakes }\end{array}$ \\
\hline $\mathrm{AH}$ & $\mathrm{AREA} \times \mathrm{HUMN}$ & 2 & $\begin{array}{l}\text { Larger lakes are more likely to be colonized by } \\
\text { fishes that are preferred by anglers than smaller lakes }\end{array}$ \\
\hline $\mathrm{DH}$ & DIST $\times$ HUMN & 2 & $\begin{array}{l}\text { Lakes in close proximity are more likely to be colonized } \\
\text { by fish that are preferred by anglers than distant lakes }\end{array}$ \\
\hline
\end{tabular}

The number of parameters was defined as the extent of lake or species information incorporated into the model information. The null model had zero parameters, models that incorporated either lake information or species information had one parameter, and models that incorporated information on lakes and species had two parameters. See text and appendices for description of probability vectors. 
sampling distributions for matrix correlations for each hypothesis. Matlab v.6.5 was used for all simulations and analyses.

An innovative method to quantify the degree of belief among models was used. This method is analogous to the Akaike Information Criterion (AIC; Burnham and Anderson 1998) and is advantageous because it can be extended to studies, such as ours, that do not involve General Linear Models. Following Occam's razor, a simple model (i.e., a model with few parameters) with a large coefficient of determination $\left(r^{2}\right)$ is most desirable, whereas a complex model (many parameters) with a small $r^{2}$ is least desirable. The AIC allows comparison of two (or more) models with a different number of parameters by penalizing each model according to the respective number of parameters. Graphically, a negatively sloping line represents the gradient from least to most desirable model (Figure 1). Our method utilizes this graphical representation. The median coefficient of determination $\left(r^{2}\right)$ value of the 1000 iterations for each model was adjusted graphically by the number of parameters to determine which model best fit the observed data. The null model was considered to have zero parameters, models that incorporated either lake information or species information to have one parameter, and models that incorporated information on lakes and species to have two parameters (Table 2). Each alternate model was plotted by weighting the correlation four times that of the number of parameters (i.e., $r^{2}$ was multiplied by 4 ) because we desired to rank the matrix correlation greater than the number of parameters; that is, we subjectively (as was also done with the AIC) determined the extent of the penalty for additional parameters. Graphing the respective coordinates for each model and transferring each point to the gradient line using a perpendicular line that intersected the coordinate accomplished the adjustment. The position of each model on the gradient line provides a visual representation of the relative fit of each model to the observed data. For example, two hypothetical models, $\mathrm{M}$ and $\mathrm{N}$, each have an $r^{2}$ of 0.4 and model $\mathrm{M}$ has twice as many parameters as model $\mathrm{N}$. Occam's razor suggests that model $\mathrm{N}$ is preferred to model M. Likewise, another hypothetical model, $\mathrm{O}$, with an $r^{2}$ of 0.7 and the same number of parameters as model $\mathrm{N}$, is preferred to both models $\mathrm{M}$ and $\mathrm{N}$. Graphical representation using our method ranks these hypothetical models with model $\mathrm{O}$ being most preferred (closest to most desirable model) and model $\mathrm{M}$ being least preferred (closest to least desirable model) (Figure 1).

\section{Results}

The overall fit of the models was dependent on the question asked of the Jaccard's index. Jaccard's

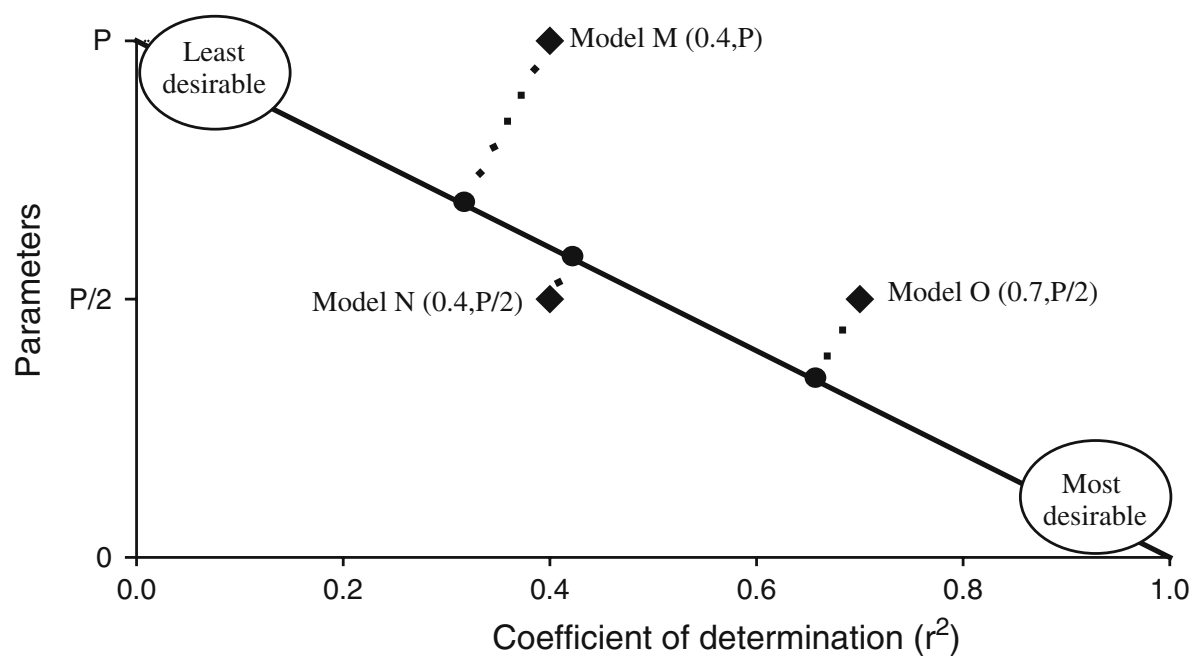

Figure 1. Visual illustration of a model's fit to the data with adjustment of the coefficient of determination based on the number of parameters. Three hypothetical models $(\mathrm{M}, \mathrm{N}$, and $\mathrm{O})$ are presented. The fit of these models is determined by the models' respective intersection on the worse to best-fit gradient line. 
index can be used to answer two very different questions, which corresponds to Q-mode and R-mode analysis in the ecological literature. (1) How similar are lakes with respect to species composition? (2) How similar are species with respect to the lakes they occupy? For the first question (Q-mode analysis), the most desirable model was LS (Figure 2); the alternative hypotheses we developed did not account for empirical observations beyond the null model. This is not to say that ecological mechanisms were not structuring the communities; rather, observed patterns among lakes are inconsistent with those produced by fish invasiveness, angler preference, lake area, and distance among lakes. Of the proposed mechanisms, however, lake area did have the greatest correlation with empirical observations, but the correlations themselves were insignificant (Figure 3). Perhaps the more meaningful question is question two because we were interested in biological characteristics (e.g., species invasiveness) and human activities (e.g., stocking) that were responsible for the observed distribution of species. For the second question (R-mode analysis), the most desirable model was LI (Figure 4), which accounted for empirical observations beyond the null model. The invasiveness models (i.e., LI, DI and AI) were the only models to result in significant correlations in all 1000 iterations (Figure 5). Differing from the first question, LS resulted in the lowest mean correlation of -0.0049 (95\% CI: $-0.323,0.313$ ). The best fitting models were the fish invasiveness models with LI having a slightly greater mean correlation $(0.4319$ [95\% CI: $0.275,0.589])$ than DI $(0.4275$ [95\% CI: 0.268 , $0.587])$ and AI (0.4121 [95\% CI: $0.253,0.571])$. All of these models outperformed the human preferences models (Figure 5), which we expected to be the best fitting models. In fact, model rankings based on mean correlation values and parsimony from best fit to least fit were LI, LS, DI, AI, AS, LH, DS, DH and AH (Figure 4).

\section{Discussion}

For this particular study, multiple hypotheses allowed a previous bias towards angler preference to be bypassed by a completely different structuring mechanism, fish invasiveness. This methodology is becoming increasingly popular despite its divergence from the classical view of hypothesis testing (Hilborn and Mangel 1997). Traditional scientific methodology dictates that a single hypothesis is tested through carefully designed experiments (Platt 1964), often using arbitrarily chosen

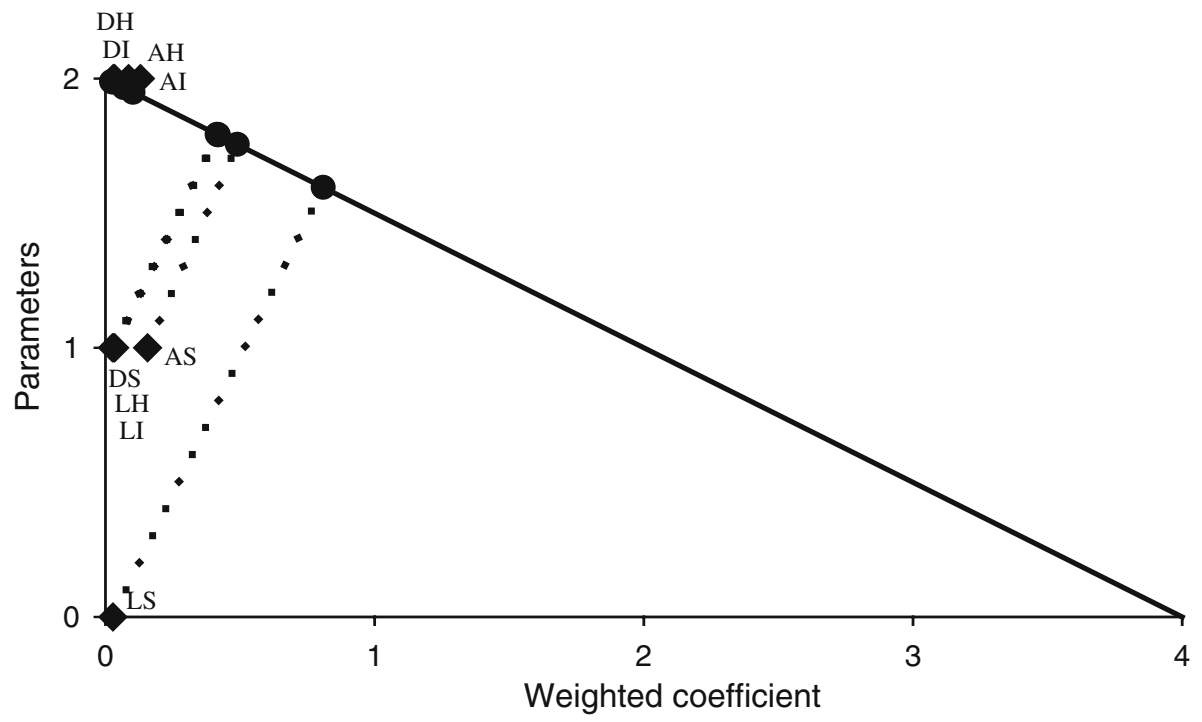

Figure 2. Visual depictions of the adjusted correlations after penalizing for the number of parameters to answer the question, how similar are lakes in terms of species composition? Acronyms correspond to respective hypotheses that are defined (Table 2) and discussed in text. The number of parameters was defined as the extent of lake or species information incorporated into the model information. The coefficient of determination was weighted four times the number of parameters. 

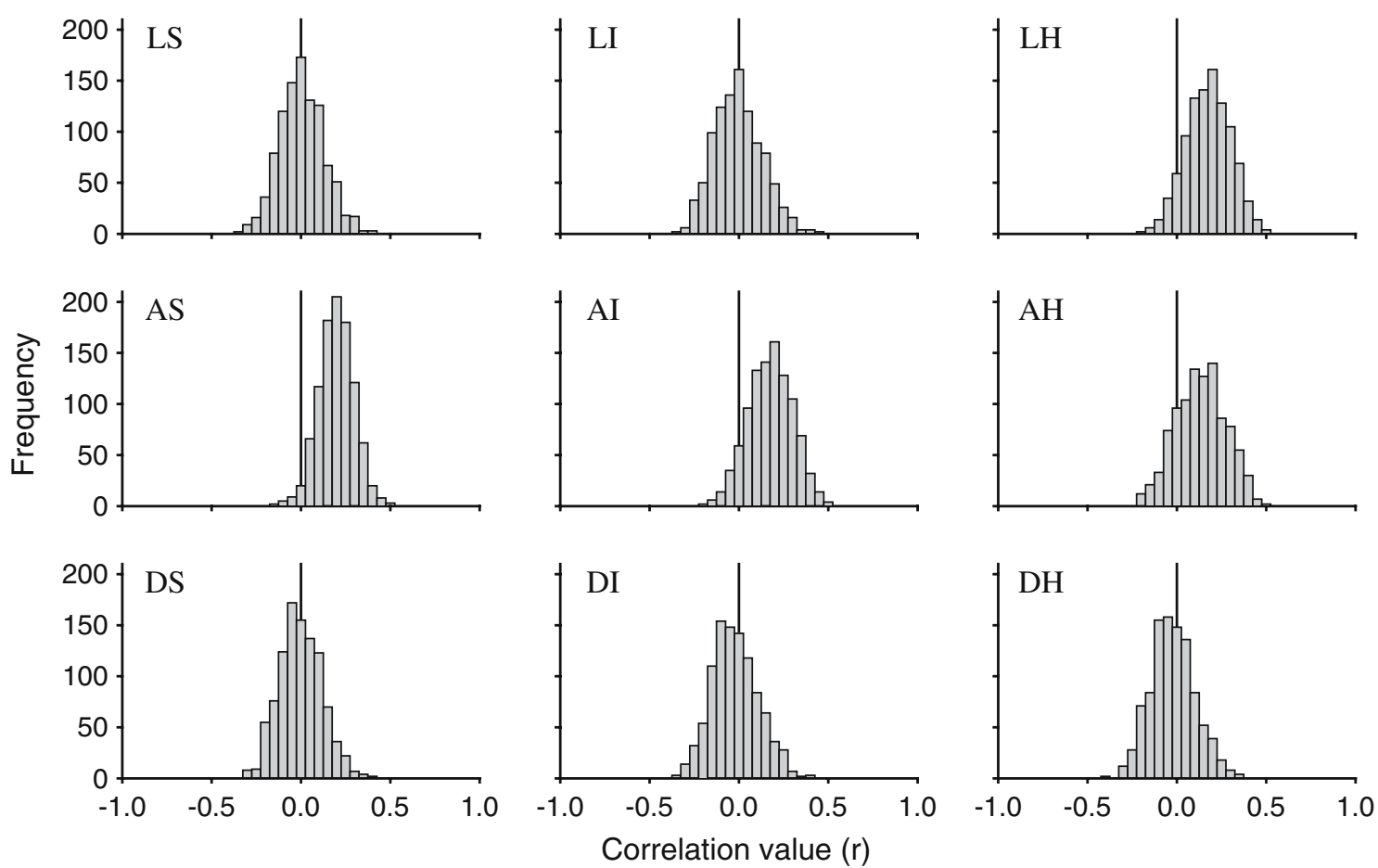

Figure 3. Correlations of the nine models using 1000 iterations of Mantel's test comparing the observed presence-absence matrix to nine probability models to answer the question how similar are lakes in terms of species composition? Acronyms correspond to respective hypotheses that are defined (Table 2) and discussed in text.

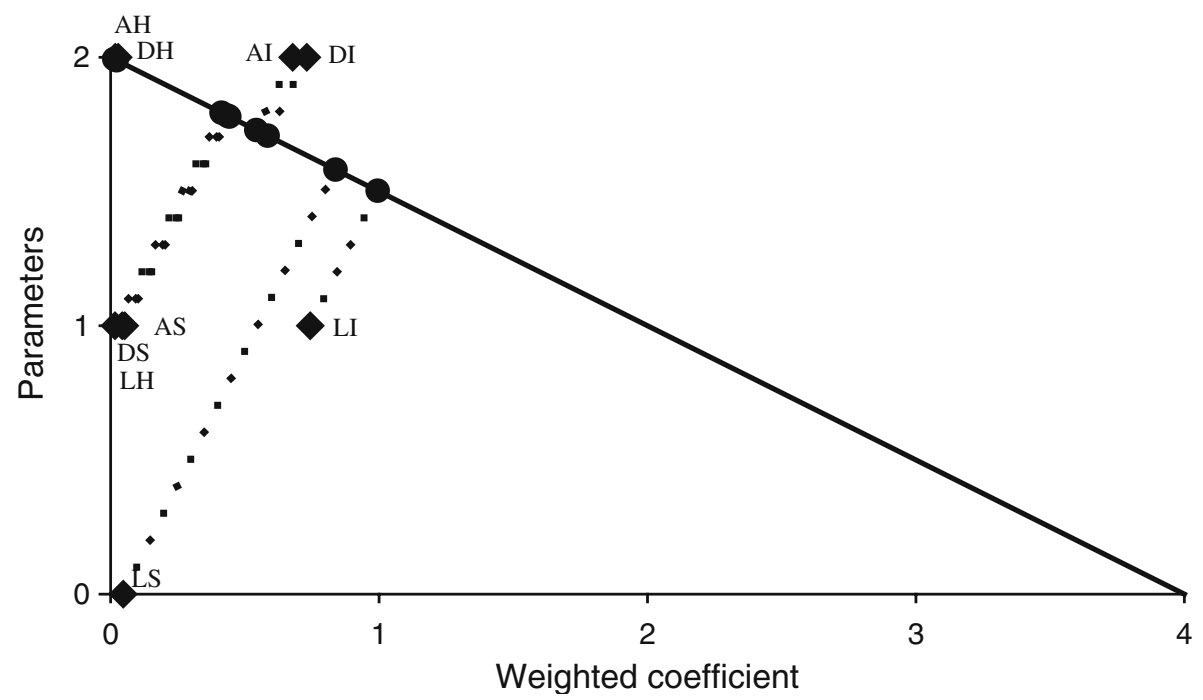

Figure 4. Visual depictions of the adjusted correlations after penalizing for the number of parameters to answer the question, how similar are species in terms of lakes they occupy? Acronyms correspond to respective hypotheses that are defined (Table 2) and discussed in text. The number of parameters was defined as the extent of lake or species information incorporated into the model information. The coefficient of determination was weighted four times the number of parameters. 

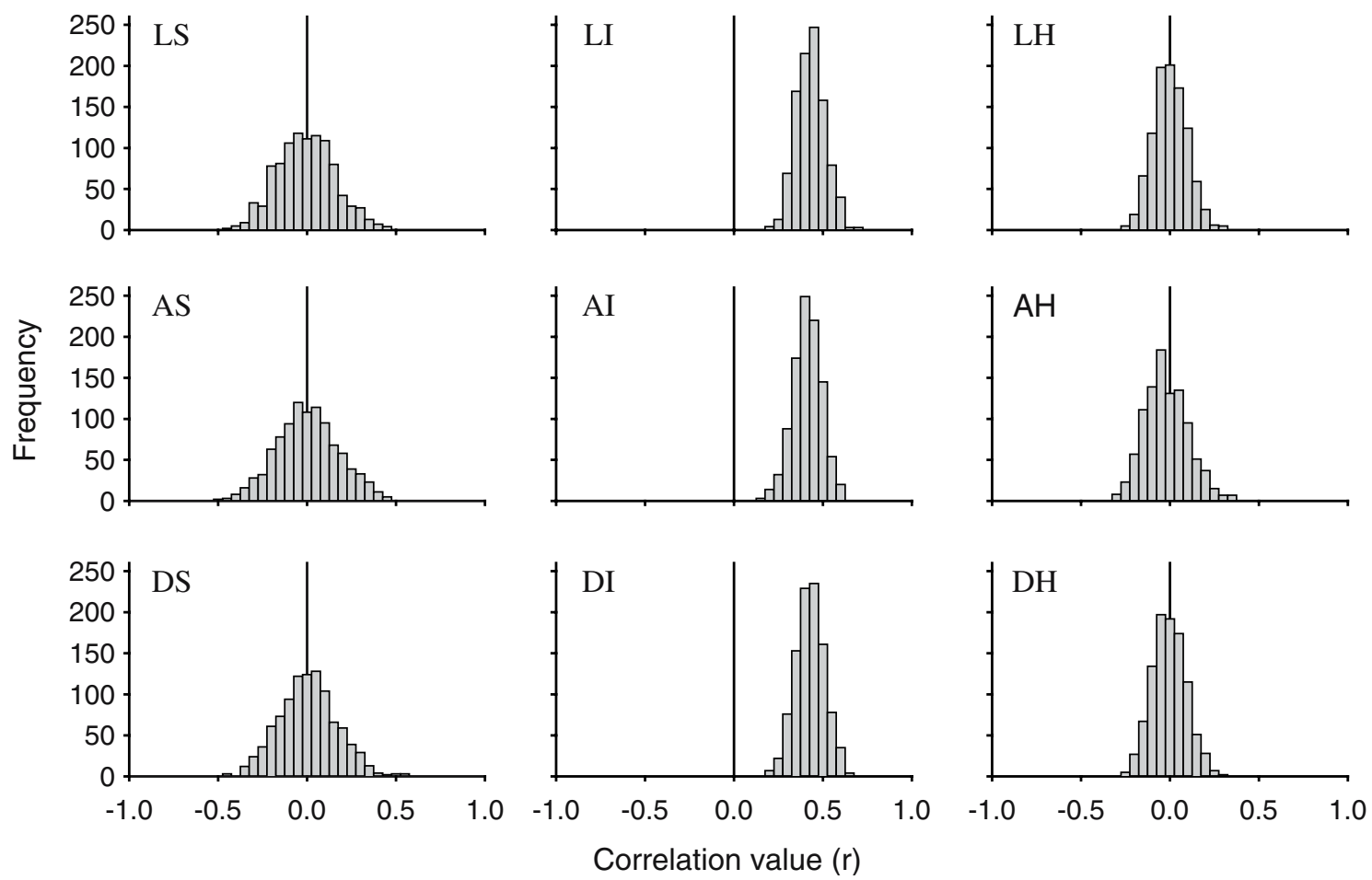

Figure 5. Correlations of the nine models using 1000 iterations of Mantel's test comparing the observed presence-absence matrix to nine probability models to answer the question, how similar are species in terms of the lakes they inhabit? Acronyms correspond to respective hypotheses that are defined (Table 2) and discussed in text.

significance values. In this situation, scientists seek to reject the hypothesis of no relationship to gain evidence of an alternative hypothesis. However, only in rare instances is it impossible to reject the null hypothesis (Meehl 1967, 1978; Cohen 1990; Hubbard 2004); that is, many null hypotheses are constructed such that they function as a 'straw man' in which they are almost invariably rejected. This results in most studies claiming an effect, especially when sample sizes are large. However, an alternate view of the scientific method has emerged wherein data are confronted against multiple competing hypotheses. Multiple hypotheses testing allows a suite of hypotheses, formulated as models, to be tested against each other using the data to state the degree of belief among models (Hilborn and Mangel 1997). When searching for an ecological mechanism, it seems more compelling to test observed data against a suite of hypotheses rather than a lone hypothesis because ecological dynamics are complex and often involve multiple mechanisms.
Although fish invasiveness was not the hypothesized model that we originally postulated to best fit the data, it does represent a biologically plausible mechanism. In fact, it incorporates more biological realism than the human preference models, which were based on the idea that humans played the major role of dispersion of these fishes without regard for biological differences among the species. Simply put, most introductions are not initially successful and require multiple attempts to colonize an ecological system (e.g., Forsyth et al. 2001; Haccou and Vatutin 2003). The invasiveness models incorporated species-specific information of tolerance to disturbance and fecundity, though there is an entire suite of characteristics (Moyle and Light 1996; Kolar and Lodge 2002) that plays a role in invasion success. In contrast, HUMN models did not incorporate species-specific information on the likelihood of successful introductions. Even though a species may be more favored by humans, it will ultimately be the individual biology of the organism that will determine the 
species' success in the habitat, or water body. Hence, organismal biology is a prime component in the homogenization of fauna.

There are a number of limitations to the analysis that warrant mention. Most are a result of limitations with the available data. First, electrofishing is size-selective (Zalewski and Cowx 1990; Meador and McIntyre 2003). Small species (e.g., inland silverside Menidia beryllina, red shiner Cyprinella lutrensis, and western mosquito fish Gambusia affinis), known to occur in Lubbock lakes, were not captured during sampling and consequently were not included in the assessment. This gear selection bias was not detrimental to the assessment, which focused on the fishes that are most valuable to humans and most likely to be introduced by citizens. It was suspected that inclusion of smaller species in our assessment would not qualitatively change our results. Second, this assessment was limited to one city, which may or may not be representative of other urban centers. Extinction of fishes was not an issue in Lubbock because none of the urbanized water bodies historically supported viable fish populations; hence, no indigenous fish species were found within this system. Distribution of fishes in other urbanized centers that historically supported fishes would likely be influenced by both introductions and extinctions. Third, it is possible that the invasiveness of common carp was an overriding factor in the goodness of fit for the invasiveness models because this species had greater than an order of magnitude chance of invasion over all other species. However, there was likely little variation in outcomes among iterations given this large degree of invasiveness (i.e., it is likely that presence of common carp will be predicted for all lakes in most model runs). Furthermore, the presence of common carp in $95 \%$ of Lubbock lakes likely leads to no difference among the models ability to predict presence of common carp. In reality, it is likely that the occurrence of less invasive species is responsible for the goodness of fit of invasiveness models. Fourth, although human preference models did not perform well, it was believed that humans are still potentially important in determining the distribution of fish species among urban lakes. Clearly, invasion success is influenced by biological characteristics of species, such as growth rates, trophic status, and reproductive life history (Byers and Goldwasser 2001), and environmental characteristics, such as disturbed or degraded habitat, productivity, and species composition (Simberloff 1986; Lodge 1993; Moyle and Light 1996; Reusch 1998; Levine and D'Antonio 1999). All else being equal, the probability of successful invasion increases with increasing propagule pressure, which is a function of frequency of introduction attempts and the number of individuals introduced (Levine 2000; Kolar and Lodge 2001; Semmens et al. 2004). Unfortunately, stocking efforts by TPWD were responsible for a minor component of the distribution of fishes in Lubbock lakes and there are no data available that provide insights about illegal propagule pressure in urban lakes, which were needed for development of more appropriate human-influence models. We suggest that propagule pressure from illegal introductions would initially be related to lake age until a threshold would be reached. Exploration of this hypothesis will require long-term data of fish assemblages in urban settings.

The patterns of biotic homogenization are becoming better understood in both aquatic ( $\mathrm{Ra}$ hel 2002) and terrestrial (McKinney and Lockwood 2001) ecosystems; however, the mechanisms underlying current patterns of biotic homogenization remain undeveloped, preventing the ability to predict specific patterns of homogenization (Olden and Poff 2003). Because the components that drive biotic homogenization are dynamic, patterns of homogenization will not occur at a similar rate across geographic regions. Herein, a suite of hypotheses was tested to determine which mechanism was most responsible for the process of invasion within an urbanized ecosystem. Speciesspecific characteristics were found to be the most important factor in determining incidence of fishes. Increased understanding of these underlying mechanisms of biotic homogenization will allow for greater predictability of circumstances that lead to similarity among communities.

It has been proposed that the world's human population will double in the next 50 years, which will increase the prevalence of anthropogenic disturbances in ecological systems. Additionally, projections suggest that greater than $60 \%$ of the world's population will live in cities by the year 2030 (United Nations Population Division 2001). The urban ecosystem will be an important topic for ecological study as anthropogenic forces through chemical, biotic, and physical disturbances more 
intensely affect ecosystem composition and function. A primary concern will be minimization of biotic homogenization of the world's flora and fauna, of which humans are a vital component. Humans primarily affect biotic homogenization through human-mediated habitat homogenization and large-scale introductions of a limited number of species. With a continuation of biotic homogenization, ecological patterns in urban ecosystems will no longer be explained by current understanding of ecological mechanisms such as natural dispersion and coevolution; instead, concepts that incorporate the role of anthropogenic forces, such as fragmented and exotic habitats, tolerance to disturbance, and ability to adapt to invading species, will be needed to explain community composition and ecosystem function. It will be this understanding of the role of human-mediated forces in ecological study that will allow a reduction in the rate of worldwide biologic impoverishment.

\section{Acknowledgements}

We thank N. Crouch, D. DeLeon, J. Hoy, J. Smith, and B. Van Zee for assistance with field sampling and N. McIntyre, G. Perry, R. Strauss, and $\mathrm{G}$. Wilde for valuable discussion and comments. Sampling of wild fish was conducted with approval from the Texas Tech University Animal Care and Use Committee, Protocol \# 99867A. This is manuscript number T-9-1073 of the College of Agricultural Sciences and Natural Resources, Texas Tech University.

\section{Appendix A}

Species vectors used to develop probability matrices that corresponded to alternate hypotheses. The below probabilities are row vectors, though listed as column vectors for ease of reading. SPEC is the equiprobable vector for species occurrence. HUMN is the human preference vector based on the preference of Lubbock anglers for targeted species. INVA vector is the invasiveness vector based on the fecundity and tolerance of species found in Lubbock lakes. Refer to the text for specific details on vector calculation.

\begin{tabular}{llll}
\hline Species & SPEC & HUMN & INVA \\
\hline Ameiurus melas & 0.083 & 0.009 & 0.005 \\
Carassius auratus & 0.083 & 0.009 & 0.017 \\
Cyprinus carpio & 0.083 & 0.019 & 0.716 \\
Dorosoma cepedianum & 0.083 & 0.009 & 0.119 \\
Ictalurus punctatus & 0.083 & 0.312 & 0.045 \\
Lepomis cyanellus & 0.083 & 0.009 & 0.004 \\
Lepomis humilis & 0.083 & 0.009 & 0.002 \\
Lepomis macrochirus & 0.083 & 0.005 & 0.017 \\
Lepomis megalotis & 0.083 & 0.009 & 0.002 \\
Micropterus salmoides & 0.083 & 0.494 & 0.018 \\
Pomoxis annularis & 0.083 & 0.057 & 0.052 \\
Pomoxis nigromaculatus & 0.083 & 0.057 & 0.012 \\
\hline
\end{tabular}

\section{Appendix B}

Playa vectors used to develop probability matrices that corresponded to alternate hypotheses. LAKE is the equiprobable vector for any species to occur in any Lubbock lake. DIST is the vector that relates distance from other urban lakes for any species to occur in the lake given that lakes in close geographic proximity are likely to have similarly occurring species. AREA is the area vector that gives a greater probability of any species to occur within larger lakes. Refer to the text for specific details on vector calculation.

\begin{tabular}{llll}
\hline $\begin{array}{l}\text { Urban playa } \\
\text { lake }\end{array}$ & LAKE & DIST & AREA \\
\hline Andrews & 0.0588 & 0.0420 & 0.1162 \\
Casey & 0.0588 & 0.0529 & 0.0387 \\
Crow & 0.0588 & 0.0616 & 0.0317 \\
Dupree & 0.0588 & 0.0466 & 0.0863 \\
Elmore & 0.0588 & 0.0626 & 0.1567 \\
Guy & 0.0588 & 0.0580 & 0.0387 \\
Higinbotham & 0.0588 & 0.0746 & 0.0475 \\
Hoel & 0.0588 & 0.0531 & 0.0158 \\
Jennings & 0.0588 & 0.0520 & 0.0317 \\
Leftwich & 0.0588 & 0.0373 & 0.0863 \\
Long & 0.0588 & 0.0528 & 0.0775 \\
Mahon & 0.0588 & 0.0553 & 0.1567 \\
Maxey & 0.0588 & 0.0638 & 0.007 \\
McCullogh & 0.0588 & 0.0403 & 0.0317 \\
Miller & 0.0588 & 0.0650 & 0.0387 \\
Ribble & 0.0588 & 0.1346 & 0.0229 \\
Stevens & 0.0588 & 0.0475 & 0.0158 \\
\hline
\end{tabular}

\section{References}

Beckman W.C.1952. Guide to the Fishes of Colorado. University of Colorado Museum, Boulder, CO. 
Blair R.B. 2001. Birds and butterflies along urban gradients in two ecoregions of the United States: is urbanization creating a homogeneous fauna?. In: Lockwood J.L. and McKinney M.L. (eds), Biotic Homogenization, Kluwer Academic/Plenum Publishers, New York, New York, pp. 33-56.

Bodola A. 1966. Life history of the gizzard shad, Dorosoma cepedianum (Le Sueur), in western Lake Erie. US Fish Wildl Serv Fish Bull 65: 391-425.

Burnham K.P. and Anderson D.R. 1998. Model Selection and Inference: A Practical Information-Theoretic Approach. Springer-Verlag, New York.

Byers J.E. and Goldwasser L. 2001. Exposing the mechanism and timing of impact of non-indigenous species on native species. Ecology 82: 1330-1343.

Carlander K.D. 1953. Handbook of Freshwater Fishery Biology with First Supplement. W.C. Brown Co., Dubuque, Indiana.

Cohen J. 1990. Statistical Power Analysis for the Behavioral Sciences. Lawrence Erlbaum Associates, Inc., Hillsdale, NJ.

Connor E.F. and McCoy E.D. 1979. The statistics and biology of the species-area relationship. Am. Nat. 113: 791-833.

Courtenay W.R. Jr. and Stauffer J.R. Jr. 1990. The introduced fish problem and the aquarium fish industry. J. World Aquacult. Soc. 21: 145-159.

Cowie R.H. 2001. Decline and homogenization of Pacific faunas: the land snails of American Samoa. Biol. Conserv. 99: 207-222.

Duncan J.R. and Lockwood J.L. 2001. Spatial homogenization of the aquatic fauna of Tennessee: extinction and invasion following land use change and habitat alteration. In: Lockwood J.L. and McKinney M.L. (eds), Biotic Homogenization, Kluwer Academic/Plenum Publishers, New York, pp. 245-257.

Forsyth D.M., Duncan R.P. and Simberloff D. 2001. Propagule size and the relative success of exotic ungulate and bird introductions to New Zealand. Am. Nat. 157: 583.

Gotelli N.J. and Graves G.R. 1996. Null Models in Ecology. Smithsonian Institution Press, Washington, DC.

Grimm N.B., Grove J.M., Pickett S.T.A. and Redman C.L. 2000. Integrated approaches to long-term studies or urban ecological systems. BioScience 50: 571-584.

Haccou P. and Vatutin V. 2003. Establishment success and extinction risk in autocorrelated environments. Theoret. Popul. Biol. 64: 303-314.

Hilborn R. and Mangel M.1997. The Ecological Detective: Confronting Models with Data. Princeton University Press, Princeton, NJ.

Hubbard R. 2004. Blurring the distinctions between p's and alpha's in psychological research. Theory Psychol. 14: 295327.

Jaccard P. 1908. Nouvelles Récherches sur la Distribution Florale. Bull Soc Vaudoise Sci Natur 44: 223-270.

Kelly J.W. 1962. Sexual maturity and fecundity of the largemouth bass, Micropterus salmoides (Lacepede), in Maine. Trans. Am. Fish Soc. 91: 23-28.

Kolar C.S. and Lodge D.M. 2001. Progress in invasion biology: predicting invaders. Trends Ecol Evol 16: 199-204.

Kolar C.S. and Lodge D.M. 2002. Ecological predictions and risk assessment for alien fishes in North America. Science 298: 1233-1236.
Kolz A.L. and Reynolds J.B. 1990. A power threshold method for the estimation of fish conductivity. In: Cowx I.G. (ed.), Developments in electric fishing, Fishing News Books, Osney Mead, Oxford, pp. 5-9.

Lever C.1996. Naturalized Fish of the World. Academic Press, San Diego, CA.

Levine J.M. 2000. Species diversity and biological invasions: relating local process to community pattern. Science 288 : 852-854.

Levine J.M. and D'Antonio C.M. 1999. Introduced fishes in marine systems and inland. Oikos 87: 15-26.

Linam G.W., Kleinsasser L.J. and Mayes K.B. 2002. Regionalization of the index of biotic integrity for Texas streams. Texas Parks and Wildlife Department, River Studies Report No. 17, Austin, TX.

Lockwood J.L., Brooks T.M. and McKinney M.L. 2000. Taxonomic homogenization of global avifauna. Anim. Conserv. 3: 27-35.

Lodge D.M. 1993. Biological invasions: lessons for ecology. Trends Ecol. Evol. 8: 133-137.

Lopinot A. 1961. The redear sunfish. Ill. Widl. 17: 3-4.

Ludwig H.R. Jr. and Leitch J.A. 1996. Inter-basin transfer of aquatic biota via anglers' bait buckets. Fisheries 21: 14-18.

MacArthur R.H. and Wilson E.O. 1963. An equilibrium theory of insular zoogeography. Evolution 17: 373-387.

MacArthur R.H. and Wilson E.O.1967. The Theory of Island Biogeography. Princeton University Press, Princeton, NJ.

Mack R.N., Simberloff D., Lonsdale W.M., Evans H., Clout M. and Bazzaz F.A. 2000. Biotic invasions: Causes, epidemiology, global consequences, and control. Ecol. Appl. 10: 689-710.

Mantel N. 1967. The detection of disease clustering and a generalized regression approach. Cancer Res. 27: 209-227.

Marchetti M.P., Light T., Feliciano J., Armstrong T., Hogan Z., Viers J. and Moyle P.B. 2001. Homogenization of California's fish fauna through abiotic change. In: Lockwood J.L. and McKinney M.L. (eds), Biotic Homogenization, Kluwer Academic/Plenum Publishers, New York, pp. 259278.

Marchetti M.P., Moyle P.B. and Levine R. 2004. Invasive species profiling? Exploring the characteristics of non-native fishes across invasion stages in California. Freshwater Biol. 49: 646-661.

McDonnell M.J. and Pickett S.T.A.1993. Humans as Components of Ecosystems: the Ecology of Subtle Human Effects and Populated Areas. Springer-Verlag, New York.

McKinney M.L. 2002. Urbanization, biodiversity, and conservation. BioScience 52: 883-890.

McKinney M.L. and Lockwood J.L. 1999. Biotic homogenization: a few winners replacing many losers in the next mass extinction. Trends Ecol. Evol. 14: 450-453.

McKinney M.L. and Lockwood J.L. 2001. Biotic homogenization: a sequential and selective process. In: Lockwood J.L. and McKinney M.L. (eds), Biotic Homogenization, Kluwer Academic/Plenum Publishers, New York, pp. 1-17.

McMahon T.E. and Bennett D.H. 1996. Walleye and northern pike: Boost or bane to northwest fisheries. Fisheries 21: 6-13.

Meador M.R. and McIntyre J.P. 2003. Effects of electrofishing gear type on spatial and temporal variability in fish community sampling. Trans. Am. Fish Soc. 132: 709-716. 
Meehl P.E. 1967. Theory-testing in psychology and physics: a methodological paradox. Philos. Sci. 34: 103-115.

Meehl P.E. 1978. Theoretical risk and tabular risk: Sir Karl, Sir Ronald, and the slow progress of soft psychology. J. Consult. Clin. Psychol. 46: 806-834.

Morgan G.D. 1954. The life history of the white crappie (Pomoxis annularis) of Buckeye Lake. Ohio J. Sci. 43: 113144.

Moyle P.B.1976. Inland Fishes of California. University of California Press, Berkeley, CA.

Moyle P.B. and Light T. 1996. Biological invasions of fresh water: empirical rules and assembly theory. Biol. Conserv. 78: 149-161.

Olden J.D. and Poff N.L. 2003. Toward a mechanistic understanding and prediction of biotic homogenization. Am. Nat. 162: 442-460.

Olden J.D. and Poff N.L. 2004. Ecological processes driving biotic homogenization: testing a mechanistic model using fish faunas. Ecology 18: 1865-1875.

Olden J.D., Poff N.L., Douglas M.R., Douglas M.E. and Fausch K.D. 2004. Ecological and evolutionary consequences of biotic homogenization. Trends Ecol. Evol. 19: 1824.

Oliver I., Holmes A., Dangerfield J.M., Gillings M., Pik A.J., Britton D.R., Holley M., Montgomery M.E., Raison M., Logan V., Pressey R.L. and Beattie A.J. 2004. Land systems as surrogates for biodiversity in conservation planning. Ecol. Appl. 14: 485-503.

Platt J.R. 1964. Strong inference. Science 146: 347-353.

Radomski P.J. and Goeman T.J. 1995. The homogenizing of Minnesota lake fish assemblages. Fisheries 20: 20-23.

Rahel F.J. 2000. Homogenization of fish faunas across the United States. Science 288: 854-856.

Rahel F.J. 2002. Homogenization of freshwater faunas. Annu. Rev. Ecol. Syst. 33: 291-315.

Reynolds J.B. 1996. Electrofishing. In: Murphy B.R. and Willis D.W. (eds), Fisheries Techniques, 2nd edAmerican Fisheries Society, Bethesda, MD, pp. 221-253.

Reusch T.B.H. 1998. Native predators contribute to invasion resistance to the non-indigenous bivalve Musculista senhousia in southern California, USA. Marine Ecol. Progr. Ser. 170: 159-168.

Rooney T.P., Wiegmann S.M., Rogers D.A. and Waller D.M. 2004. Biotic impoverishment and homogenization in unfragmented forest understory communities. Conserv. Biol. 18: 787-798.

Rosenzweig M.L. 2001. The four questions: what does the introduction of exotic species do to diversity. Evol. Ecol. Res. 3: $361-367$.

Schramm H.L. Jr., Black R.C., Molhage T.R., Ramsey R.H., Smith L.M. and Urban L.V. 1992. Fisheries, waterfowl, and recreation in an urban stormwater management system. In: Jensen R. (ed.), Solutions to non-point source pollution, Texas Water Resource Institute, College Station, TX, pp. 6577.

Scott M.C. and Helfman G.S. 2001. Native invasions, homogenization, and the mismeasure of integrity of fish assemblages. Fisheries 26: 6-15.

Scott W.B. and Crossman E.J. 1973. Freshwater fishes of Canada. Bull. Fish Res. Board Can. 184: 1-966.

Selmi S. and Boulinier T. 2004. Distribution-abundance relationship for passerines breeding in Tunisian oases: test of the sampling hypothesis. Oecologia 139: 440-445.

Semmens B.X., Buhle E.R., Salomon A.K. and PattengillSemmens C.V. 2004. A hotspot of non-native marine fishes: evidence for the aquarium trade as an invasion pathway. Mar. Ecol. Progr. Ser. 266: 239-244.

Shavlik, C.E. 2000. An assessment of largemouth bass and panfish population dynamics in west Texas ponds. Master's Thesis. Texas Tech University, Lubbock, TX.

Simberloff D. 1986. Introduced insects: a biogeographic and systematic perspective. In: Mooney H.A. and Drake J.A. (eds), Ecology of Biological Invasions of North America and Hawaii Ecological Studies, Vol. 58. Springer-Verlag, New York, pp. 3-26.

Smith L.M.2003. Playas of the Great Plains. University of Texas Press, Austin, TX.

Swee U.B. and McCrimmon H.R. 1966. Reproductive biology of the carp, Cyprinus carpio L., in Lake St. Lawrence, Ontario. Trans. Am. Fish Soc. 95: 372-380.

Tilman D. 1999. The ecological consequences of changes in biodiversity: a search for general principles. Ecology 80 : 1455-1474.

Toetz D.W. 1965. Factors affecting the survival of bluegill sunfish larvae. Bloomington, IN.

Turner W.R., Nakamura T. and Dinetti M. 2004. Global urbanization and the separation of humans from nature. BioScience 54: 585-590.

United Nations Population Division (2001) World population prospects: the 2000 revision, New York, NY.

Vitousek P.M., Mooney H.A., Lubchenco J. and Melillo J.M. 1997. Human domination of Earth's ecosystems. Science 277: 494-499.

Wilson K.J. 1997. Extinct and introduced vertebrate species in New Zealand: a loss of biodistinctiveness and gain in biodiversity. Pac. Conserv. Biol. 3: 301-305.

Zalewski M. and Cowx I.G. 1990. Factors affecting the efficiency of electric fishing. In: Cowx I.G. and Lamarque P. (eds), Fishing with Electricity Applications in Freshwater Fisheries Management, Fishing News Books, Osney Mead, Oxford, pp. 89-111. 